\title{
ESTIMATION OF THE MODULUS OF ELASTICITY FOR DAM CONCRETE
}

\author{
J. Vilardell, A. Aguado, L. Agulló and R. Gettu \\ Universitat Politècnica de Catalunya, Department of Construction Engineering, \\ ETSECCPB-UPC, Edificio C-1, Gran Capitán s/n, 08034 Barcelona, Spain.
}

\begin{abstract}
The modulus of elasticity of dam concrete is difficult to determine directly from tests due to the necessity for large specimens and testing machines. In order to study the applicability of simple elastic models for predicting the modulus from standard size specimens, tests were conducted on prisms of $45 \times 45 \times 90 \mathrm{~cm}$ fabricated with dam concrete (maximum aggregate of $120 \mathrm{~mm}$ ). The tests on standard $15 \times 30 \mathrm{~cm}$ cylinders were made with the mortar and wet-screened components of this concrete. It is seen that the use of the data from these components together with estimated values of the modulus of the aggregates gives reasonable predictions of the moduli of the dam concrete. This has been verified for a range of ages, from 7 to 180 days.
\end{abstract}

\section{Introduction}

The modulus of elasticity of concrete is a parameter necessary in structural analysis for the determination of the strain distributions and displacements, especially when the design of the structure is based on elasticity considerations. This property is conventionally measured using standardized tests based on small specimens subjected to uniaxial compression loading. The specimen dimensions are taken to be at least three times the maximum aggregate size of the concrete. Furthermore, empirical expressions developed from experimental studies are available to estimate the modulus of elasticity from the compressive strength, which is a standard measure for characterizing concrete.

The concrete used in the construction of dams is often composed of a binder containing cement and a high amount of fly ash, and aggregates with a maximum size ranging from 80 to $200 \mathrm{~mm}$. The compressive strength of these concretes has to be measured with large 
specimens, for example cylinders of $45 \times 90 \mathrm{~cm}$ (1). Due to practical difficulties in performing such tests, dam concrete is usually wet-screened, removing aggregates larger than about $40 \mathrm{~mm}$, and standard cylinders of $15 \times 30 \mathrm{~cm}$ are cast and tested in compression (2). However, this procedure can result in the overestimation of the compressive strength (3); Tuthill et al. (1) suggest that the strength of the dam concrete be taken as $85 \%$ of the wetscreened concrete, when specific test data are lacking.

A procedure similar to that for the compressive strength has at times been adopted for the experimental determination of the modulus of elasticity, where tests are performed on conventional-size specimens made from wet-screened concrete (4). More often, the empirical expressions for conventional concrete are used to estimate the modulus of elasticity from the compressive strength. Such approaches neglect the effect of aggregate and specimen size on the modulus, which can be significant and vary with the age of the dam concrete (5).

In the present work, tests on prisms of $45 \times 45 \times 90 \mathrm{~cm}$ made with dam concrete (maximum aggregate size $=120 \mathrm{~mm}$ ), and on cylinders made with the wet-screened concrete (maximum aggregate size $=40 \mathrm{~mm}$ ) and the mortar of the dam concrete (maximum aggregate size $=5 \mathrm{~mm}$ ) were performed. The objective was to study the relations between the moduli of elasticity determined from the different specimens, and to evaluate the possibility of using an elastic two-phase composite model to estimate the modulus of the dam concrete.

\section{Experimental details and results}

The concrete used in the study corresponds to that used in the construction of the Llosa del Cavall double arch dam on the River Cardener in Catalunya, Spain. The nominal composition of the dam concrete had the following proportions, per cubic meter: Spanish type I 45A (CEN Class I 42.5R): $130 \mathrm{~kg}$, fly ash: $89 \mathrm{~kg}$, fine sand $(0-1.25 \mathrm{~mm}): 398 \mathrm{~kg}$, coarse sand $(1.25-5 \mathrm{~mm}): 234 \mathrm{~kg}$, fine gravel $(5-20 \mathrm{~mm}): 392 \mathrm{~kg}$, medium gravel $(20-60$ $\mathrm{mm}): 646 \mathrm{~kg}$, coarse gravel $(60-120 \mathrm{~mm}): 558 \mathrm{~kg}$, plasticizer: 0.55 liters, and water: $45 \mathrm{~kg}$. The aggregates used were obtained along the River Segre near the location of the dam, and were identified to be mainly limestone. In addition to the dam concrete, the mortar corresponding to this concrete was fabricated with the components up to the grain size of 5 $\mathrm{mm}$ (i.e., excluding the gravels). The dam concrete was also sieved to remove gravel of size larger than $40 \mathrm{~mm}$, and is denoted as wet-screened concrete. The mortar and the concretes were fabricated in a plant at the site of the dam.

Standard cylinders of $15 \times 30 \mathrm{~cm}$ were cast in steel molds for the mortar and the wetscreened concrete. Such cylinders could not be cast for the dam concrete since the diameter of the cylinder was almost the same as the maximum aggregate size of $120 \mathrm{~mm}$. 
Therefore, larger prismatic specimens of $45 \times 45 \times 90 \mathrm{~cm}$ were cast from the dam concrete using laminated plywood molds. Note that the height/width ratio was equal to 2 in both the specimen geometries.

The specimens were loaded in uniaxial compression in a $4.5 \mathrm{MN}$ servohydraulic crushing machine with an MTS 458 closed-loop controller. The cylinders were loaded at the piston displacement rate of $0.004 \mathrm{~mm} / \mathrm{s}$ and the prisms at a rate of $0.012 \mathrm{~mm} / \mathrm{s}$, producing the same nominal axial strain rate. The rates corresponded to that needed to reach failure in the cylinders after about 4 minutes. In the cylinder tests, the loading was stopped at intervals corresponding to $10 \%$ of the failure stress in order to record the deformations. In the prisms, the loading was stopped at intervals of $10 \%$ of the failure stress obtained in the wet-screened cylinders, in the 7-day tests, and at intervals of approximately $500 \mathrm{kN}$, in the others. The tests were performed at 7, 28, 90 and 180 days after casting.

The deformation of each cylinder was measured through 3 strain gauges placed in the middle along the axis. The lengths of the strain gages were $30 \mathrm{~mm}$ and $120 \mathrm{~mm}$ for the mortar and wet-screened concrete, respectively. For the prisms, reference discs were glued on two opposite vertical faces as shown in Fig. 1, and a DEMEC-type mechanical extensometer, of $15 \mathrm{~cm}$ gage length, was used to manually obtain the displacement between adjacent discs. The deformations of the strain gages were made through a computer-based data acquisition system.

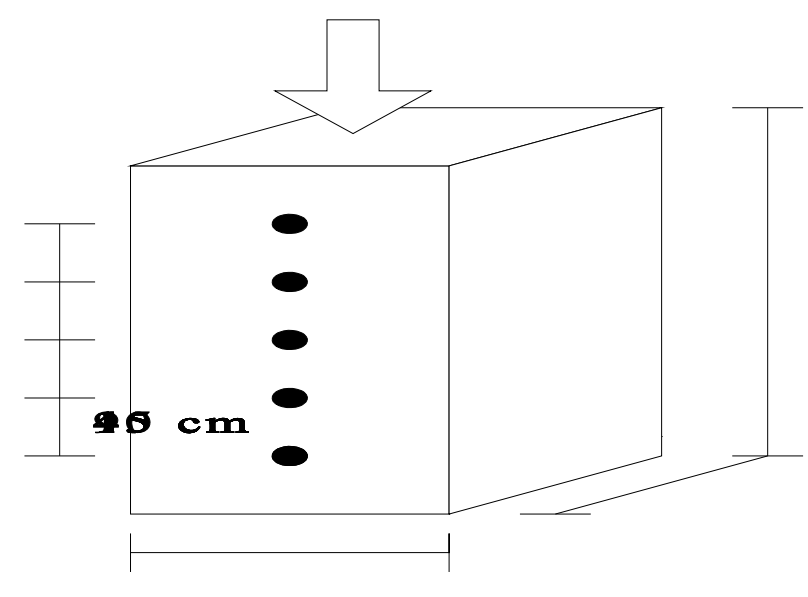

FIG. 1

The configuration of reference discs for deformation measurement

Typical stress-strain curves for the three materials at different ages are presented in Fig. 2 a-c. The curves are plotted almost until failure in the case of the cylinders, and until a load of $2 \mathrm{MN}$ for the prisms (Fig. 2c; note the different scales). It can be seen that until the 
stresses of at least $30 \%$ of the maximum, the curves are practically linear. Therefore, the modulus of elasticity was taken as the average slope of the curves between $10 \%$ and $30 \%$ of the maximum stress. 

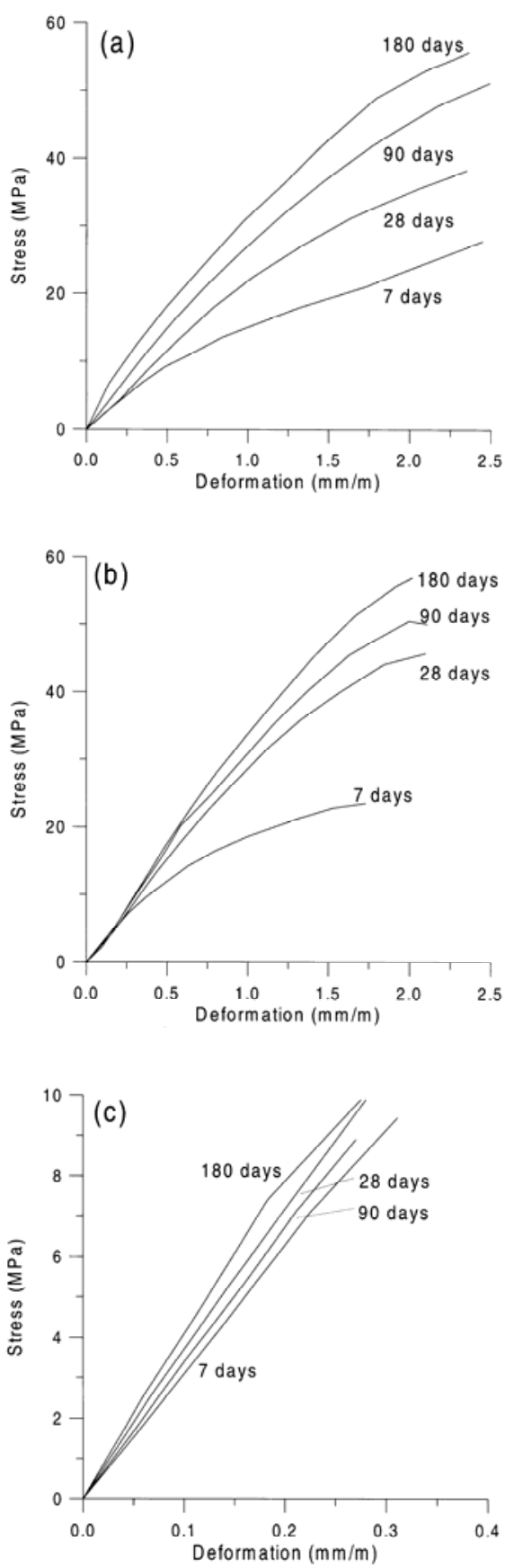

FIG. 2 a-c

Stress-strain curves for (a) mortar, (b) wet-screened concrete and (c) dam concrete, at different ages 
The average values of the modulus obtained for each material, along with the coefficient of variation in parentheses, are given in Table 1 . It can be seen that the values of $E$ increase with age in each material. Moreover, the modulus of the dam concrete $\left(E_{d c}\right)$ is higher than that of the wet-screened concrete $\left(E_{\text {wsc }}\right)$, which is higher than that of the mortar $\left(E_{\text {mor }}\right)$; i.e., $E_{d c}>E_{w s c}>E_{m o r}$. Also, the modulus increases with a decrease in the paste content, as expected. The variability of the results in the case of the mortar (determined with standard cylinders) is small, while the variation of the dam concrete results (determined with prisms) is much higher. The compressive strengths obtained from the $15 \times 30 \mathrm{~cm}$ cylinders are presented in the same table, along with the coefficients of variation. The prisms could not be loaded to failure since the capacity of the machine was exceeded in some cases.

TABLE 1. Test Results

\begin{tabular}{|c|c|c|c|c|c|}
\hline \multirow{2}{*}{$\begin{array}{c}\text { Age } \\
\text { (days } \\
\text { ) }\end{array}$} & \multicolumn{3}{|c|}{$\begin{array}{c}\text { Modulus of elasticity } \\
\text { (GPa) }\end{array}$} & \multicolumn{2}{|c|}{$\begin{array}{c}\text { Compressive strength } \\
\text { (MPa) }\end{array}$} \\
\hline & Mortar & $\begin{array}{c}\text { Wet- } \\
\text { screened } \\
\text { concrete }\end{array}$ & $\begin{array}{c}\text { Dam } \\
\text { concrete }\end{array}$ & Mortar & $\begin{array}{c}\text { Wet- } \\
\text { screeneo } \\
\text { concrete }\end{array}$ \\
\hline 7 & $\begin{array}{c}19.6 \\
(1.9 \%) \\
\end{array}$ & $\begin{array}{c}24.8 \\
(20.4 \%) \\
\end{array}$ & $\begin{array}{c}30.3 \\
(18.2 \%) \\
\end{array}$ & $\begin{array}{c}22.8 \\
(0.2 \%) \\
\end{array}$ & $\begin{array}{c}23.7 \\
(0.9 \%) \\
\end{array}$ \\
\hline 28 & $\begin{array}{c}23.8 \\
(2.9 \%)\end{array}$ & $\begin{array}{c}34.5 \\
(4.2 \%)\end{array}$ & $\begin{array}{c}37.3 \\
(14.2 \%)\end{array}$ & $\begin{array}{c}41.4 \\
(4.2 \%)\end{array}$ & $\begin{array}{c}45.0 \\
(4.2 \%)\end{array}$ \\
\hline 90 & $\begin{array}{c}28.2 \\
(4.6 \%) \\
\end{array}$ & $\begin{array}{c}35.1 \\
(1.2 \%) \\
\end{array}$ & $\begin{array}{c}43.0 \\
(16.1 \%)\end{array}$ & $\begin{array}{c}52.6 \\
(1.1 \%) \\
\end{array}$ & $\begin{array}{c}50.7 \\
(2.3 \%) \\
\end{array}$ \\
\hline 180 & $\begin{array}{c}30.7 \\
(3.1 \%)\end{array}$ & $\begin{array}{c}37.2 \\
(5.0 \%)\end{array}$ & $\begin{array}{c}42.2 \\
(11.0 \%)\end{array}$ & $\begin{array}{c}60.8 \\
(1.8 \%)\end{array}$ & $\begin{array}{c}56.9 \\
(2.3 \%)\end{array}$ \\
\hline
\end{tabular}

\section{Prediction of the Elastic Modulus of the Dam Concrete}

Since it is practically cumbersome to test large specimens, it is proposed here that the elastic modulus obtained from conventional specimens $(15 \times 30 \mathrm{~cm}$ cylinders $)$ of mortar and/or wet-screened concrete, along with the modulus of the gravel, be used to estimate the modulus of elasticity of the dam concrete. A simple composite model is used for this purpose.

Most composite models for describing the elastic behavior of two phase materials are basically combinations of parallel and series phase arrangements, as shown in Fig. 3 for the models of Hirsch and Counto (6). For applying these models, the basic assumptions are that (a) concrete is a three-dimensional combination of two homogeneous and isotropic phases: the matrix phase and the coarse aggregates; and (b) each phase behaves linearly in the linear elastic regime of the concrete. Also, it is necessary to know the mix proportions of the concrete, the unit weights of the aggregates or their volume fractions, and the 
modulus of elasticity of each phase. 

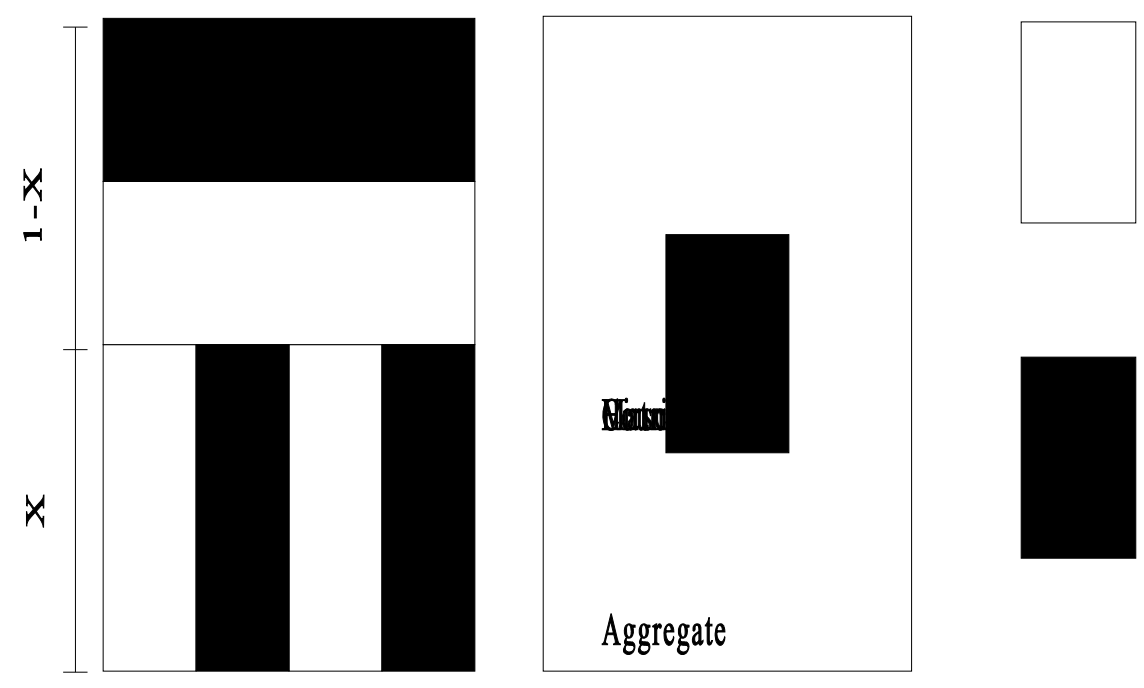

FIG. 3

Multiphase models of Hirsch and Counto

The modulus of elasticity of the concrete is given by the expressions in Equations 1 and 2 for the Hirsch and Counto models (Fig. 3), respectively (6). The Hirsch model is configured with the relative proportions of the parallel (uniform strain model) and series (uniform stress model) components as $\mathrm{x}:(1-\mathrm{x})$. 


$$
\frac{1}{E_{c}\left(V_{m}, V_{a}, E_{m}, E_{a}\right)}=x\left(\frac{1}{V_{m} E_{m}+V_{a} E_{a}}\right)+(1-x)\left(\frac{V_{m}}{E_{m}}+\frac{V_{a}}{E_{a}}\right)
$$

$$
E_{c}\left(V_{a}, E_{m}, E_{a}\right)=\frac{1}{\frac{1 \sqrt{V_{a}}}{E_{m}}+\frac{1}{\frac{1 \sqrt{V_{a}}}{\sqrt{V_{a}}} E_{m}+E_{a}}}
$$

where $E_{c}, E_{m}$ and $E_{a}$ are the elastic moduli of the composite, matrix and aggregate, respectively, and $V_{m}$ and $V_{a}$ are the volume fractions of the matrix and aggregate. In the calculations that follow, a value of $x=0.5$ was used in the Hirsch model, following other works $(6,7)$, which corresponds to an equal distribution of the parallel and series phases.

As explained earlier, the moduli of the mortar and the wet-screened concrete have been obtained experimentally using standard size specimens. Since the river gravels were mixes of different mineralogies, predominantly limestone, a range of modulus of elasticity values is possible; the range used here for the predictions is $35-65 \mathrm{GPa}(8)$. With these values, the moduli of the dam concrete is calculated and compared with the experimental data.

By taking the matrix phase as the mortar and the aggregate phase as the gravel of 5-40 $\mathrm{mm}$, the prediction of the wet-screened concrete modulus, denoted as WS(M), can be obtained from the models. Similarly, with the matrix phase as the mortar and the aggregate phase as the gravel of $5-120 \mathrm{~mm}$, the prediction can be made for the dam concrete, denoted as $\mathrm{D}(\mathrm{M})$. Alternatively, the wet-screened concrete can be considered as the matrix phase and the gravel of $40-120 \mathrm{~mm}$ as the aggregate phase to predict the modulus of the dam concrete, denoted $\mathrm{D}(\mathrm{WS})$. The results of these three simulations are given in Table 2 for the age of 90 days, which is a usual reference age for dam concretes. The values in parentheses are the errors with respect to the experimentally obtained data given in Table 1. Note that the error is calculated as the difference between the prediction and the experimental data, expressed as a percentage of the latter (where a positive sign indicates that the predicted value is lower than the actual value).

TABLE 2. $E_{c}$ Predictions (in GPa) of the Two Models for Different Aggregate Moduli, at 90 days 


\begin{tabular}{|l|c|c|c|c|c|c|}
\hline model & \multicolumn{3}{|c|}{ Hirsch model } & \multicolumn{3}{c|}{ Counto model } \\
\hline simulation & WS(M) & $\mathrm{D}(\mathrm{M})$ & $\mathrm{D}(\mathrm{WS})$ & $\mathrm{WS}(\mathrm{M})$ & $\mathrm{D}(\mathrm{M})$ & $\mathrm{D}(\mathrm{WS})$ \\
\hline $\begin{array}{l}\text { prediction (error \%) } \\
\text { with } E_{a}=35 \mathrm{GPa}\end{array}$ & $\begin{array}{c}31.0 \\
(+11.7)\end{array}$ & $\begin{array}{c}32.1 \\
(+25.4)\end{array}$ & $\begin{array}{c}35.1 \\
(+18.3)\end{array}$ & $\begin{array}{c}31.1 \\
(+11.6)\end{array}$ & $\begin{array}{c}32.1 \\
(+25.3)\end{array}$ & $\begin{array}{c}35.1 \\
(+18.3)\end{array}$ \\
\hline prediction (error \%) & $\begin{array}{c}36.4 \\
\text { with } E_{a}=50 \mathrm{GPa}\end{array}$ & $\begin{array}{c}39.6 \\
(-3.5)\end{array}$ & $\begin{array}{c}38.7 \\
(+9.9)\end{array}$ & $\begin{array}{c}36.5 \\
(-3.7)\end{array}$ & $\begin{array}{c}39.6 \\
(+7.7)\end{array}$ & $\begin{array}{c}38.8 \\
(+9.7)\end{array}$ \\
\hline prediction (error \%) & $\begin{array}{c}40.8 \\
\text { with } E_{a}=65 \mathrm{GPa}\end{array}$ & $\begin{array}{c}47.8 \\
(-16.2)\end{array}$ & $\begin{array}{c}41.7 \\
(-13.2)\end{array}$ & $\begin{array}{c}40.9 \\
(+3.0)\end{array}$ & $\begin{array}{c}47.8 \\
(-16.3)\end{array}$ & $\begin{array}{c}41.9 \\
(+2.5)\end{array}$ \\
\hline
\end{tabular}

It can be seen from the table that the predictions of the Hirsch and Counto models are practically identical. This was true for all the ages studied here. Therefore, further comparisons are made only with the Hirsch model.

The predictions of the Hirsch model at different ages are given in Table 3. It can be seen that the best predictions for the wet-screened concrete, WS(M), are obtained with an aggregate modulus of $50 \mathrm{GPa}$. At this value the dam concrete moduli are also best estimated with both simulations $D(M)$ and $D(W S)$, using the experimental data from the mortar and wet-screened concrete, respectively.

Table 3. Predictions of the Hirsch model for different aggregate moduli and the corresponding errors, for wet-screened and dam concretes

\begin{tabular}{|l|c|l|l|l|}
\hline $\begin{array}{l}\text { Age } \\
\text { (days) }\end{array}$ & $\begin{array}{c}E_{a} \\
(\mathrm{GPa})\end{array}$ & \multicolumn{1}{|c|}{$\mathrm{WS}(\mathrm{M})$} & \multicolumn{1}{|c|}{$\mathrm{D}(\mathrm{M})$} & \multicolumn{1}{|c|}{$\mathrm{D}(\mathrm{WS})$} \\
\hline \multirow{3}{*}{7 days } & 35 & $25.3(-2.0 \%)$ & $27.6(8.8 \%)$ & $27.3(9.8 \%)$ \\
\cline { 2 - 5 } & 50 & $29.6(-19.3 \%)$ & $33.9(-11.9 \%)$ & $30.2(0.3 \%)$ \\
\cline { 2 - 5 } & 65 & $33.1(-33.4 \%)$ & $39.1(-29.0 \%)$ & $32.6(-7.7 \%)$ \\
\hline \multirow{3}{*}{28 days } & 35 & $28.3(18.1 \%)$ & $29.9(19.6 \%)$ & $34.6(7.0 \%)$ \\
\cline { 2 - 5 } & 50 & $33.1(4.1 \%)$ & $36.9(1.0 \%)$ & $38.2(-2.6 \%)$ \\
\cline { 2 - 5 } & 65 & $37.1(-7.5 \%)$ & $42.7(-14.7 \%)$ & $\begin{array}{l}41.2(-10.5 \\
\%)\end{array}$ \\
\hline \multirow{2}{*}{90 days } & 35 & $31.0(11.7 \%)$ & $32.1(25.4 \%)$ & $\begin{array}{l}35.1(18.3 \\
\%)\end{array}$ \\
\cline { 2 - 5 } & 50 & $36.4(-3.5 \%)$ & $39.6(7.9 \%)$ & $38.7(9.9 \%)$ \\
\cline { 2 - 5 } & & & &
\end{tabular}




\begin{tabular}{|l|l|l|l|l|}
\cline { 2 - 5 } & 65 & $40.8(-16.2 \%)$ & $46.1(-7.2 \%)$ & $41.7(3.0 \%)$ \\
\hline 180 days & 35 & $32.6(12.5 \%)$ & $33.2(21.4 \%)$ & $\begin{array}{l}35.6(13.4 \\
\%)\end{array}$ \\
\cline { 2 - 5 } & 50 & $38.2(-2.6 \%)$ & $41.0(2.8 \%)$ & $40.3(4.5 \%)$ \\
\cline { 2 - 5 } & 65 & $42.9(-15.2 \%)$ & $47.8(-13.2 \%)$ & $43.4(-2.8 \%)$ \\
\hline
\end{tabular}

It can also be seen that the use of a relatively wide range of elastic modulus values (35-65 $\mathrm{GPa}$ ) for the aggregates leads to errors comparable to the variations normally seen in experimental data. This implies that when actual data for the aggregates are lacking or when their mineralogy cannot be determined with exactitude, it is possible to approximately predict the dam concrete modulus using a reasonable range of elastic modulus values for the aggregates.

The prediction $D(W S)$ from the experimental data of the wet-screened concrete is much better than $D(M)$ obtained from the mortar data. The error is generally less than $15 \%$ (except in one case), which is the accepted error in prediction formulas for the elastic modulus. Obviously, the error in $\mathrm{D}(\mathrm{WS})$ is lower since the relative contribution of the unknown aggregate modulus is lower than in the prediction based on the mortar. When an appropriate aggregate modulus is used, the two predictions are quite similar, as seen in the case of $E_{a}=50 \mathrm{GPa}$ (Fig. 4). Note that in Fig. 4, the bullets and the error bars denote the mean values and the standard deviations, respectively. 


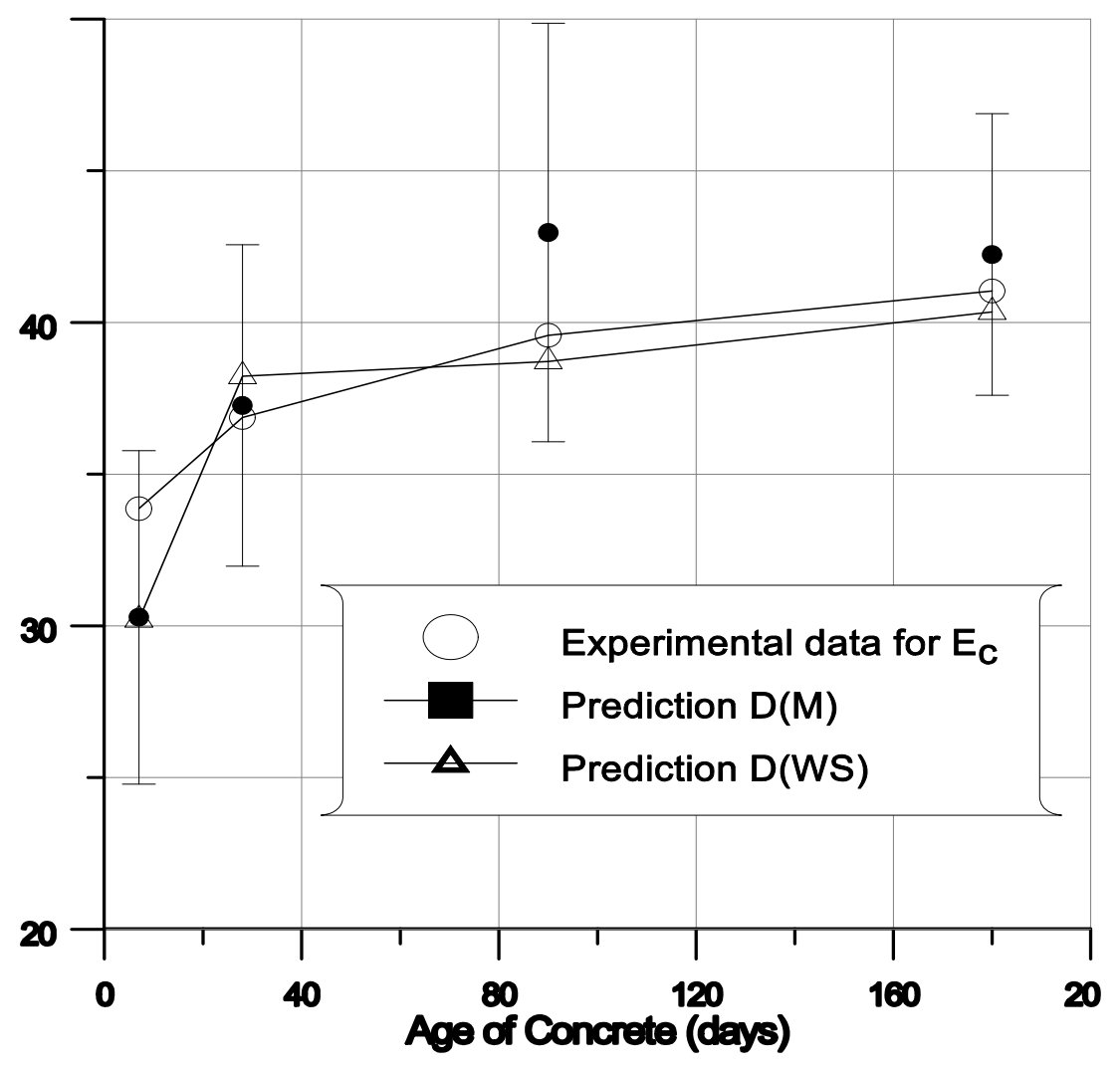

FIG. 4

Predictions with the Hirsch model and $E_{a}=50 \mathrm{GPa}$

It can also be seen in Table 3 and Fig. 4 that at 7 days the errors of the predictions based only on the mortar data are relatively high. This can be attributed to the presence of weak interfaces, whose contribution is not taken into account explicitly in the models. This effect is lower in the prediction D(WS) based on the wet-screened concrete data, making it much more reliable for practical purposes, even at early ages.

As mentioned earlier, the configuration of the Hirsch model used here has equal proportions of the parallel and series components. A more general treatment, considering this proportion as $x:(1-x)$, can be made to optimize the value of $x$. It was seen here that increasing the value of $x$ with age (i.e., increasing the parallel or uniform deformation component) decreases the error in the predictions of $E_{d c}$ made from the data of the mortar. The trends for the other simulations were inconclusive. 


\section{Conclusions}

1. Data from standard specimens of mortar and wet-screened components of dam concrete can be used in simple elastic models (e.g., models of Hirsch and Counto) along with estimations of the aggregate moduli, to obtain satisfactory predictions of the elastic modulus of dam concrete. This is practically useful since the testing of the dam concrete requires large size specimens and testing machines.

2. For practical purposes, the use of data from wet-screened concrete is recommended for predicting the elastic modulus of dam concrete, especially when the aggregate modulus is unknown.

3. The elastic modulus of dam concrete is predicted better with elastic composite models at later ages (more than 28 days), probably due to the lower contribution of weak interfaces.

\section{Acknowledgments}

Partial funding from Spanish DGICYT Grants PB95-0780, AMB96-0953 and PB93-0955 to the UPC is gratefully appreciated. The authors thank the Junta d'Aigües (Generalitat de Catalunya) and INARSA for their help in preparing the specimens and for stimulating discussions with them. The experimental work was conducted with the assistance of Miguel A. Martín at the Structural Technology Laboratory of the UPC.

\section{References}

(1) L.H.Tuthill, G.S.Sarkaria , and C.J.Cortright, Transactions of the Tenth International Congress on Large Dams (Montréal, 1970), Vol. IV, 181-197, ICOLD, Paris, 1970.

(2) R. Sánchez Trejo, Quality Control of Concrete, Report for the Committee on Materials for Dams, Bulletin 47, ICOLD, Paris, 1983.

(3) A.M.Neville, Properties of Concrete, Longman Scientific \& Technical, Harlow, UK, 1989.

(4) ACI Committee 207, Mass concrete, Report ACI 207.1R-87, American Concrete Institute, Detroit, 1987.

(5) J. Soares de Pinho, J. Mora and C.A. Florentino, Transactions of the Sixteenth International Congress on Large Dams (San Francisco, 1988), Vol. III, 483-491, ICOLD, Paris,1988.

(6) S. Mindess and J.F. Young, Concrete, Prentice-Hall, Inc., Englewood Cliffs, N.J., 1981.

(7) F.P. Zhou, F.D. Lydon and B.I.G. Barr, Cem. Concr. Res., 25, No. 1, 1995, pp. 177-186.

(8) P. Alaejos and M. Fernández, Materials and Structures, 28, No. 184, 1995, pp. 559-568. 